\title{
LUIZ FERNANDO GOUVÊA LABOURIAU (1921-1996)
}

\author{
Walter Handro ${ }^{1,2}$
}

No dia 29 de março de 1996, perdeu a Botânica brasileira, e especialmente a Fisiologia Vegetal, um de seus maiores nomes: Luiz Fernando Gouvêa Labouriau. Nascido em 22 de junho de 1921, no Rio de Janeiro, ainda menino ganhou um microscópio e um livro de História Natural, o que contribuiu para despertar-lhe um profundo interesse pela biologia, e em particular pela botânica. Aos 17 anos "descobre" a matemática, e passa um ano estudando-a profundamente, tentando construir a base do que entrevia ser o fundamento e a linguagem universal do pensamento científico. Entre 1941 e 1944 faz o curso superior na Escola Naval que, imaginava, poderia conduzi-lo a uma carreira economicamente atraente de engenharia naval. Entretanto, o apelo pela biologia e pela botânica era mais forte. Assim, entre $1944 \mathrm{e}$ 1945 vamos encontrá-lo como estagiário no Museu Nacional, e em seguida no laboratório do Prof. Miguel Ozório de Almeida, em Manguinhos (1946-47). À partir de 1946 inicia sua carreira como botânico, no Jardim Botânico do Rio de Janeiro. Ali começa a desenvolver suas pesquisas nos campos da morfologia e morfogênese experimental (Labouriau 1948, 1952, Labouriau \& Rabello 1948). Em 1952 casa-se com a bióloga Maria Léa Salgado Labouriau, hoje renomada palinóloga, que vai acompanhá-lo por toda a vida. A necessidade de uma formação mais sólida em fisiologia das plantas, leva-o aos Estados Unidos em 1953, como bolsista do recémcriado CNPq, para fazer sua pós-graduação. Na Universidade de Michigan obtém o "Arts Bachelor" (1953), por equivalência a seu curso na Escola Naval, e em seguida o Mestrado (1954), o que, segundo ele, lhe permitiu corrigir as lacunas de uma formação que considerava de autodidata. Em 1954 é aceito como aluno de doutorado no Californian Institute of Technology (CalTech), onde convive com grandes fisiologistas como Bonner, Galston, Went e Nitsch, entre outros. Sua tese é um excelente trabalho de morfogênese experimental em Pteridófitas, uma de suas paixões (Labouriau 1958). De volta ao Jardim Botânico, em 1957, inicia uma fase em que tenta

\footnotetext{
' Departamento de Botânica/IB/USP, Caixa Postal 11461, 05422-970, São Paulo, SP, Brasil.

2 Professor Titular de Fisiologia Vegetal no Depto. de Botânica, Instituto de Biociências da USP. Iniciou a carreira em 1962, ainda estudante, no Laboratório do Prof. Labouriau, que o orientou até o doutorado, em 1968.
} 


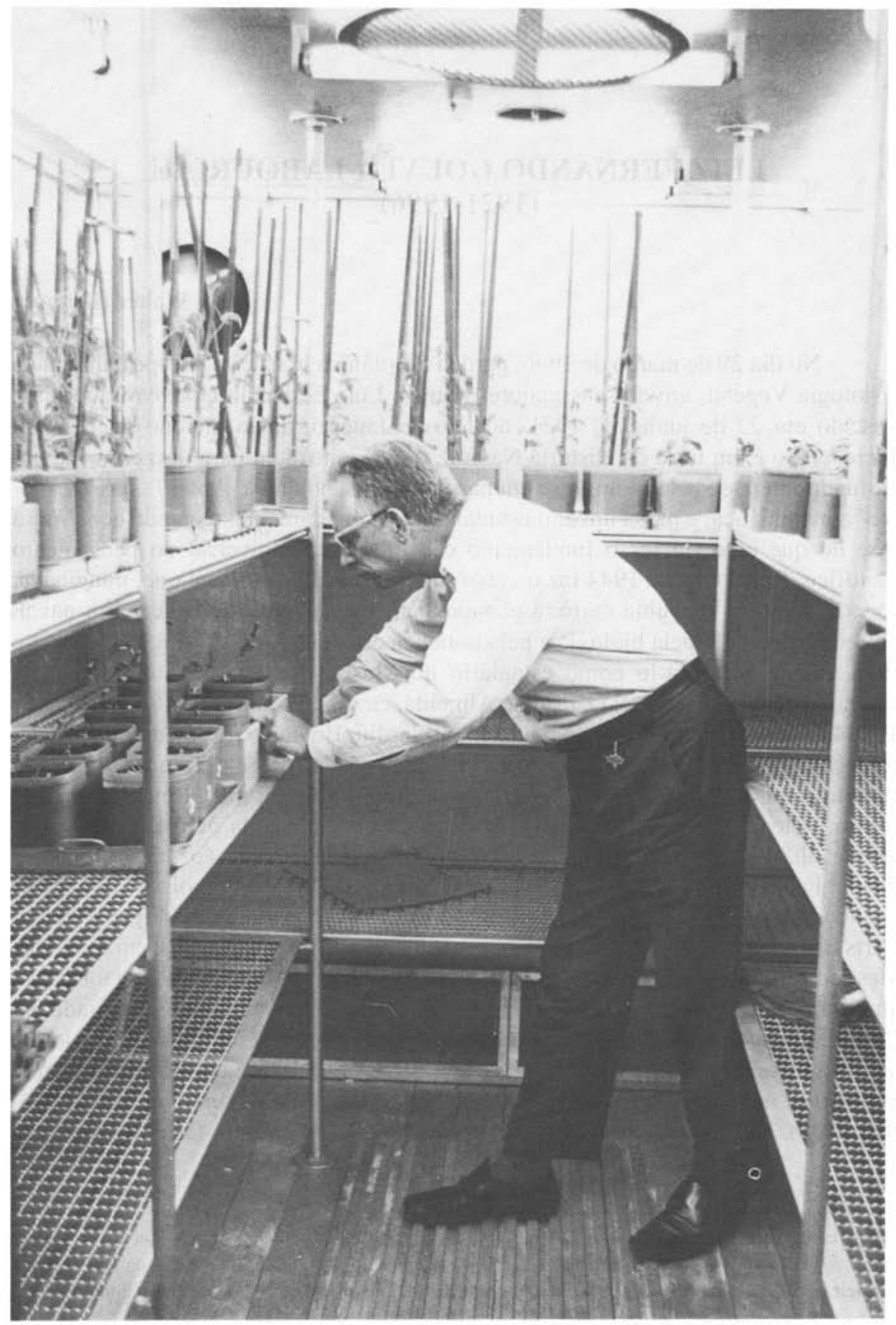


conciliar a execução de trabalhos de fisiologia ecológica e fisiologia do desenvolvimento (Labouriau et al. 1961, De la Sota \& Labouriau 1961), com a formação de novos pesquisadores (uma preocupação constante em sua vida) e a construção de um laboratório de fisiologia.

A falta de perspectivas em montar um laboratório de fisiologia vegetal no Jardim Botânico determinou sua transferência para São Paulo em 1960, para o Instituto de Botânica da Secretaria da Agricultura, onde teria a oportunidade de organizar seu primeiro laboratório. No início, sem ter ainda os recursos de espaço e equipamentos, dedicou-se a trabalhos de fisiologia e anatomia ecológica, abrindo novas perspectivas para estudos sobre os cerrados (Labouriau 1963, 1966a). Com recursos que obteve da FAPESP, CNPq e BID, conseguiu montar um excelente laboratório, onde deu início à linha de pesquisa que iria desenvolver dali em diante: a germinação de sementes e sua dependência da temperatura, que foi o tema de sua livredocência, obtida na Universidade Federal do Rio de Janeiro em 1967 (Labouriau 1970a, 1972). Nesse período trabalham sob sua orientação alguns nomes que iriam tornar-se conhecidos especialistas em fisiologia, bioquímica e química de plantas, como Ivany Válio, Gil Felippe, Sonia Dietrich, Alfredo Gui Ferreira, José Tarquínio Prisco e Lauro Morhy, entre outros. Em 1969, depois de 10 anos de esforços para obter recursos, montar seu laboratório, treinar cerca de 15 pesquisadores, publicar 18 trabalhos como autor e 25 como orientador, uma reforma administrativa no Instituto de Botânica extingue a seção que chefiava, e o transfere compulsoriamente, juntamente com sua mulher, para outra instituição sem quaisquer recursos para pesquisa em fisiologia vegetal. Não aceitando a situação, demite-se e vive durante alguns meses com uma bolsa da FAPESP.

No início de 1970, Labouriau é convidado para trabalhar na Universidade de Brasília; ali, funda o Departamento de Biologia Vegetal, e tenta organizar um novo laboratório de fisiologia. $\mathrm{O}$ ambiente da capital federal do início dos anos 70 não era muito adequado para quem desejasse trabalhar com independência e critérios de mérito, nem o apoio que recebeu foi o prometido. Assim, em 1973, muda-se para a Venezuela, onde até 1986 trabalha no IVIC (Instituto Venezolano de Investigaciones Cientificas), tendo aí obtido os títulos de Pesquisador Titular e Pesquisador Emérito. Nesse período organiza o laboratório onde desenvolve intensa atividade na linha de pesquisa que escolhera (termobiologia) (Labouriau 1978), e também como professor. Publica ainda um livro sobre a fisiologia da germinação (Labouriau 1983). Em 1985, recebe a ordem "Andrés Bello" por serviços prestados à educação na Venezuela. De volta ao Brasil, em 1986 é contratado na Universidade de Brasília como professorvisitante, lutando e conseguindo organizar seu novo laboratório, o Laboratório de Termobiologia. Em 1988 chega a Professor-Titular, e em 1991, ao atingir 70 anos, é aposentado compulsoriamente, mas continua em atividade no seu Laboratório, como Pesquisador Associado Senior, tendo recebido em 1995 o título de Professor Emérito.

A importância de Luiz Fernando Gouvêa Labouriau não pode ser visualizada apenas pelo fato de ter sido o introdutor da Fisiologia do Desenvolvimento de Plantas no Brasil, e pela sua obra de pesquisa e didática; deve ser compreendida também 
através do testemunho daqueles que tiveram o privilégio de privar com ele como colega e amigo, de assistir suas aulas, conferências, debates em sessões de congressos e acompanhá-lo na elaboração de seus trabalhos. Criado numa família de rigorosos padrões éticos, possuindo uma inteligência brilhante, dotado de uma incrível disciplina para o trabalho, era de se esperar que após cinco anos de treinamento pós-graduado em excelente instituições científicas americanas, quando voltasse ao Brasil fosse chocar-se com o marasmo, a burocracia e a falta de critérios de mérito da maioria das instituições brasileiras. A firmeza na defesa de seus princípios, seu espírito crítico e sua franqueza, aliada a uma fina, às vezes mordaz ironia, se por um lado despertavam profunda admiração, também em certas ocasiões trouxeram-lhe dissabores. Analista perspicaz dos problemas da botânica no País, sempre tinha propostas dinâmicas e originais para promover seu progresso (Labouriau 1966b, 1970b). Os obstáculos que teve que transpor na sua luta para melhorar o nível da ciência e da educação no Brasil, nunca o desanimaram: foi sempre um otimista, pronto para recomeçar tudo de novo sempre com um entusiasmo juvenil. Apesar das peripécias, em todos os lugares pelos quais passou deixou discípulos, idéias, trabalhos e respeito.

Na sua atividade como cientista destacam-se duas preocupações fundamentais: aliar a pesquisa à formação de recursos humanos de alto nível, e trabalhar dentro do maior rigor científico. Dessas preocupações resultaram trabalhos que são verdadeiros modelos de planejamento e execução, e a disseminação pelo País de um grande número de discípulos, alguns destes responsáveis pelos melhores grupos de pesquisa em fisiologia do desenvolvimento. Não podemos deixar de mencionar os inúmeros cursos que ministrou nas mais diversas instituições, o carinho que tinha pelos jovens estudantes e a admiração que neles despertava.

Ao longo de sua carreira orientou, entre outros, cerca de 45 estágios de longa duração ao nível de Pós-Graduação, incluindo teses de mestrado e doutorado. Deixou cerca de 75 trabalhos publicados, além de outros 50, que orientou mas não é co-autor. Apesar das inúmeras dificuldades que enfrentou, nos últimos 30 anos de carreira desenvolveu linha de pesquisa extremamente original e coerente, sobre a cinética da germinação e seu tratamento termodinâmico, reconhecida internacionalmente. Para tanto, muitas vezes construiu seu próprio equipamento (Labouriau 1977) e usava seus sólidos conhecimentos de matemática.Um de seus mais completos trabalhos nessa linha (Labouriau \& Pacheco 1979) mereceu destaque com detalhada análise no tratado de Bewley e Black (Bewlwy \& Black 1982). Outros trabalhos, onde utilizava água pesada, permitiram interpretações bastante originais sobre os efeitos da temperatura na estabilidade de proteinas no processo de germinação (Labouriau 1980, Borghetti \& Labouriau 1994). Ultimamente desenvolvia juntamente com sua filha, a matemática Isabel Labouriau, uma linha de pesquisa onde procurava estender para animais e microorganismos, as interpretações de processos fisiológicos cinéticos que ocorrem em plantas (Labouriau \& Labouriau 1991).

Em 29 de março (ainda bem que não foi no dia 31, diria ele!) o coração de Labouriau, que já tinha sido operado duas vezes, não resistiu ao infarto que sofrera em janeiro. Dois dias antes de sua morte conseguiu terminar, com muito esforço, a 
redação de seu último trabalho, uma nova versão de seu famoso bloco de gradiente térmico (Labouriau 1977), ferramenta de seu trabalho experimental. Deixou a lembrança de seu entusiasmo, carisma, inteligência brilhante, e principalmente, seus exemplos. Para os que não o conheceram, ficam seus trabalhos e sua lenda.

\section{Referências bibliográficas}

Bewley, J.D. \& Black, M. 1982. Physiology and Biochemistry of Seeds, vol. 2, Springer-Verlag, Berlin (citações, p. 299-303).

Borghetti, F. \& Labouriau, L.G. 1994. Inhibition of phytochrome by deuterium oxide in the germination of akenes of Cosmos sulphureus Cav. Ciência e Cultura 46: 177-181.

De la Sota, E.R. \& Labouriau, L.G. 1961. Correlaciones entre esporangios y nervadura comisural en Blechnum occidentale L. (Filices, Blechnaceae). An. Acad. Brasil. Cienc. 33: 225-235.

Labouriau, L.G. 1948. Contribuição ao estudo da morfogênese dos esporofilos de Anemia Sw. I. Teratologia dos esporofilos. Arqu. Jard. Bot. Rio de Janeiro 8: 481-516.

Labouriau, L.G. \& Rabello, C. 1948. Note sur la structure de l'exine du pollen de Lilium longiflorum St. Rodriguesia 22/23: 95-97.

Labouriau, L.G. 1952. Contribution to the study of sporophyll morphogenesis in Anemia Sw. V Correlation phenomena between fertile and sterile fronds. Rev. Brasil Biol. 12: 59-68.

Labouriau, L.G. 1958. Studies on the initiation of sporangia in ferns. Arqu. Mus. Nac. 46: 119-202.

Labouriau, L.G.; Bezerra de Oliveira, J.G. \& Zauza, G.V. 1961. Transpiração de algumas plantas da caatinga aclimatadas no Jardim Botânico do Rio de Janeiro. II - Comportamento de Capparis yco Mart. An. Acad. Brasil. Cienc. 33: 375-385.

Labouriau, L.G. 1963. Problemas da fisiologia ecológica dos cerrados. Simpósio sobre Cerrado, Ed. Univ. de São Paulo, p. 233-276.

Labouriau, L.G. 1966a. Revisão da situação da ecologia vegetal nos cerrados. An. Acad. Brasil. Cienc. 38(supl.): 5-38.

Labouriau, L.G. 1966b. Sobre a formação de novos biologistas de plantas no Brasil. O Biológico 32: 113 121/139-157.

Labouriau, L.G. 1970a. On the physiology of seed germination in Vicia graminea Sw. I. An Acad. Brasil. Cienc. 42: 235-262.

Labouriau, L.G. 1970b. Análise da situação da Botânica no Brasil e uma programação de atividade que dela resulta. Arq. Inst. Biológico 37(Supl. 1): 47-78.

Labouriau, L.G. 1972. On the physiology of seed germination in Vicia graminea Sw. II - Analysis of the temperature dependence of seed germination rates. An. Acad. Brasil. Cienc. 44: 477-534.

Labouriau, L.G. 1977. A thermal gradient block for germination experiments. Rev. Brasil. Biol. 37: 295305.

Labouriau, L.G. 1978. Seed germination as a thermobiological problem. Rad. \& Environ. Biophysics 15: 345-366.

Labouriau, L.G. 1980. Effects of deuterium oxide on the lower temperature limit of seed germination. J. Thermal Biol. 5: 113-117.

Labouriau, L.G. 1983. A germinaçāo de sementes. Monografias Científicas, OEA, Washington, 170 p.

Labouriau, L.G. \& Labouriau, I.S. 1991. The Arrhenius plot of a physiological rate process is never linear.. Ciência e Cultura, 43: 363-369.

Labouriau, L.G. \& Pacheco A., A. 1979. Isothermal germination rates in seeds of Dolichos biflorus L. Bol. Soc. Venezol. Cienc. Nat. 34: 73-112. 